\title{
KOMODITAS UNGGULAN IKAN AIR TAWAR PULAU KALIMANTAN
}

\author{
Mochammad Fattah $^{a^{*}}$, Pudji Purwanti ${ }^{a}$, Edi Susiloa ${ }^{a}$ Tiwi Nurjannati Utami ${ }^{\text {a }}$ dan Dwi Sofiati ${ }^{\mathrm{b}}$

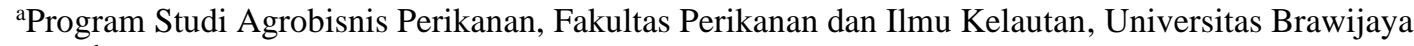 \\ ${ }^{\mathrm{b}}$ PSDKU Sosial Ekonomi, Fakultas Perikanan dan Ilmu Kelautan, Universitas Brawijaya \\ *Koresponden penulis: mochammadfattah@ub.ac.id
}

\begin{abstract}
Abstrak
Pulau Kalimantan merupakan pulau terbesar kedua di Indonesia yang mempunyai lima provinsi dengan 56 kabupaten/ kota. Produksi perikanan khususnya ikan air tawar mencapai 249.393 ton. Tujuan penelitian ini adalah menganalisis komoditas unggulan dan kontibusi ikan air tawar dari Pulau Kalimantan. Jenis penelitian yang digunakan adalah library research dengan menggunakan data sekunder dari BPS tahun 2021. Analisis data dalam penelitian ini adalah Location Quotient dan kontribusi. Jenis komoditas utama ikan air tawar yang diproduksi adalah gurame, patin, lele, nila dan ikan mas. Komoditas ikan lele merupakan ikan yang menghasilkan nilai LQ lebih besar pada 37 lokasi dan mendominasi dari komoditas sejenis. Wilayah yang berpotensi untuk dilakukan pengembangan ikan lele adalah Kalimantan Utara dan Kalimantan Barat. Namun, secara keseluruhan komoditas air tawar yang memberikan kontribusi nilai produksi tertinggi adalah Kalimantan Tengah senilai Rp.2.091 milyar atau 5,71\% dari nilai produksi sector perikanan pulau Kalimantan.
\end{abstract}

Kata kunci: komoditas unggulan, ikan air tawar, produksi ikan, provinsi

\begin{abstract}
Kalimantan Island is the second largest island in Indonesia that has five provinces with 56 districts / cities. The freshwater fish production reached 249,393 tons. This study aims to analyse leading commodities and contribution of freshwater fish from Kalimantan Island. This study uses a library research with secondary data from BPS in 2021. Location Quotient and contributions analysis are used to analyse the data. The main commodities are carp, catfish Clarias sp., catfish Pangasius sp., tilapia and carp. Catfish dominates products in 37 locations with LQ value greater than the others. The potential development areas are North Kalimantan and West Kalimantan. However, the highest production value from Kalimantan Island fishery sector is Central Kalimantan with IDR.2.091 billion or $5.71 \%$.
\end{abstract}

Keywords: leading commodities, fish fresh water, fish production, province

\section{PENDAHULUAN}

Wilayah yang mempunyai potensi perikanan perlu melakukan pengembangan sektor perikanan. Selain mampu menopang perekonomian suatu wilayah, sub sektor ini berperan dalam pemenuhan kebutuhan pangan dan gizi masyarakat [1]. Spesies ikan yang ada di Indonesia sebanyak 1193 spesies dan keanekaragaman spesies ikan air tawar Indonesia nomor tiga terkaya di dunia. Ikan air tawar di Indonesia mendiami tiga daerah sebaran geografis, yaitu: Paparan Sunda, Daerah Wallace, dan Paparan Sahul. Paparan Sunda mencakup pulau Sumatera, Jawa, Kalimantan, Bali, dan pulau-pulau kecil di sekitarnya [2]. Kalimantan merupakan pulau terbesar kedua di Indonesia dengan luas 736.000 $\mathrm{km}^{2}$ dan memiliki banyak aliran sungai [3]. Karakteristik pulau Kalimantan seperti ini memberikan potensi sumber daya ikan air laut, payau dan tawar. Produksi ikan air tawar berdasarkan data BPS Kalimantan 2021 sebanyak 249.393 ton dengan nilai Rp.6.588 milyar. Komoditi utama ikan air tawar yang dikembangkan dan dikelola Pulau Kalimantan adalah gurami, lele, patin, nila dan ikan mas. Namun, produksi 
ikan gurami hanya pada wilayah Provinsi Kalimantan Selatan.

Pengelolaan sektor perikanan dengan konsep efisiensi untuk menghasilkan keunggulan komparatif dan kompetitif melalui penentuan komoditas ikan unggulan di suatu daerah. Efisiensi dapat diwujudkan dengan menentukan komoditas ikan yang mempunyai keunggulan komparatif [4]. Komoditas unggulan adalah jenis komoditas yang diminati dan mempunyai nilai ekonomis serta mampu memberikan kontribusi pendapatan daerah lebih besar dibandingkan jenis komoditas lain atau komoditi potensial yang dipandang dapat dipersaingkan dengan produk sejenis di daerah lain [5], [6].

Komoditas yang dapat dikatakan unggul akan memberikan nilai pertumbuhan yang positif sehingga berpengaruh terhadap kontribusi pada sektor perikanan [7]. Sektor perikanan memberikan kontribusi terhadap Produk Domestik Regional Bruto (PDRB) Pulau Kalimantan sebesar $3,27 \%$ apabila dibandingkan dengan Produk Domestik Bruto Indonesia sebesar 3,7\% (PDB) sehingga kontribusi sektor perikanan pulau Kalimantan mendekati kontribusi tingkat nasional. Kontribusi perikanan tangkap dan budidaya di Pulau Kalimantan pada tahun 2020 berdasarkan data BPS senilai Rp.36.629 milyar. Tujuan dari penelitian ini adalah menganalisis komoditas unggulan dan kontribusi ikan air tawar dari Pulau Kalimantan.

\section{METODE}

Penelitian ini menggunakan jenis penelitian library research. [8] Studi kepustakaan (library research) adalah teknik pengumpulan data dengan menelaah buku, literatur, catatan, serta berbagai laporan untuk menyelesaikan masalah.

Penelitian ini dilaksanakan pada bulan Maret 2021 dengan menggunakan data sekunder. Sumber data tahun 2021 diperoleh dari data BPS Kalimantan Timur [9], Kalimantan Barat [10], Kalimantan Utara [11], Kalimantan Selatan [12], dan Kalimantan Tengah [13]. Analisis data yang digunakan menggunakan kontribusi nilai ikan air tawar dan Location Quotient (LQ) untuk mengukur komoditas unggulan. [14] Komoditas unggulan adalah produk sektoral atau kegiatan ekonomi melayani baik pasar domestik maupun pasar luar daerah dan khususnya pasar ekspor. Rumus LQ [15], sebagai berikut:

$$
L Q=\frac{\frac{v_{i}}{v_{t}}}{/ \frac{V_{i}}{V_{t}}}
$$

Dimana: $\mathrm{v}_{\mathrm{i}}=$ volume produksi provinsi komoditi ikan-i, $\mathrm{v}_{\mathrm{t}}=$ volume produksi ikan air tawar provinsi, $\mathrm{V}_{\mathrm{i}}=$ volume produksi pulau Kalimantan komoditi $\mathrm{ikan}-\mathrm{i}, \mathrm{V}_{\mathrm{t}}=$ volume produksi ikan air tawar pulau Kalimantan.

Sedangkan rumus kontribusi perikanan air tawar [16], sebagai berikut:

$$
\text { Kontribusi }=\frac{N P K_{i}}{N P S P}
$$

Dimana: $\mathrm{NPK}_{\mathrm{i}}=$ nilai produksi komoditi ikan-i, NPSP = nilai produksi ikan air tawar provinsi/ pulau Kalimantan.

\section{HASIL DAN PEMBAHASAN \\ Komoditas Unggulan Pulau Kalimantan}

Pulau Kalimantan mempunyai lima Provinsi, yaitu: Kalimantan Timur, Kalimantan Barat, Kalimantan Utara, Kalimantan Selatan, dan Kalimantan Tengah. Produksi ikan air tawar yang paling tinggi adalah Kalimantan Selatan sebesar 86.650 ton dengan 13 Kabupaten/ Kota. Kabupaten yang menghasilkan produksi tertinggi adalah Kabupaten Banjar Kalimantan Selatan sebesar 53.122 ton. Sedangkan posisi kedua adalah Kabupaten Kutai Kartanegara Kalimantan Timur sebesar 44.271 ton. Komoditas ikan air tawar yang dihasilkan dari setiap Provinsi di Pulau Kalimantan dikatakan unggul apabila LQ >1. [17] LQ > 1 mempunyai arti bahwa tingkat spesialisasi sektor i di daerah Kabupaten lebih besar dibandingkan dengan sektor yang sama 
dalam perekonomian Provinsi. Selain itu, [18] LQ >1 merupakan sektor dikatakan menjadi basis atau menjadi sumber pertumbuhan atau sektor mempunyai keunggulan komparatif serta hasil produksi tidak hanya memenuhi kebutuhan di wilayah bersangkutan akan tetapi juga dapat diekspor ke luar wilayah.

\section{Komoditas Unggulan Ikan Air Tawar Kalimantan Timur}

Komoditas utama ikan air tawar Kalimantan Timur, terdiri dari: patin, lele, nila dan ikan mas yang menyebar di 10 Kabupaten/ Kota. Pada Gambar 1. menunjukkan bahwa nilai LQ lebih kecil 1 untuk ikan patin sebanyak 8 lokasi, ikan lele sebanyak 1 lokasi, ikan nila sebanyak 6 lokasi, dan ikan mas sebanyak 9. Komoditas yang menghasilkan nilai LQ lebih besar 1 untuk ikan patin sebanyak 2 lokasi, ikan lele sebanyak 9 lokasi, ikan nila sebanyak 4 lokasi, dan ikan mas sebanyak 1 lokasi. Komoditas yang menghasilkan nilai LQ paling tinggi adalah ikan lele yang terletak pada wilayah Kota Balikpapan. Secara umum ikan lele di Kalimantan Timur mendominasi dari Provinsi lain di Pulau Kalimantan karena 9 lokasi menghasilkan nilai LQ yang lebih tinggi dari komoditas sejenis, kecuali Kabupaten Kutai Kartanegara. Pengembangan komoditas unggulan ikan air tawar pada wilayah Kabupaten Kutai Barat adalah ikan patin, ikan nila pada wilayah Kabupaten Kutai Timur, dan ikan mas pada wilayah Kabupaten Kutai Kartanegara.

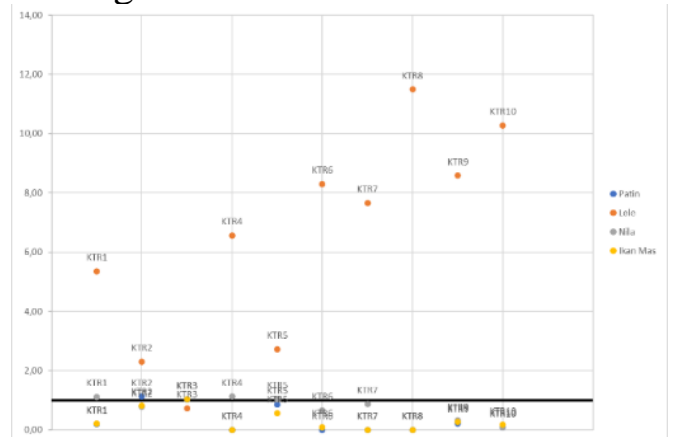

Gambar 1. Nilai LQ Ikan Air Tawar Kalimantan Timur

\section{Komoditas Unggulan Ikan Air Tawar Kalimantan Barat}

Kalimantan Barat mempunyai empat komoditas ikan air tawar dengan 14 Kabupaten/ Kota, yaitu: patin, lele, nila, dan ikan mas. Hasil perhitungan LQ pada Gambar 2. yang menghasilkan nilai di bawah 1 untuk ikan patin sebanyak 11 lokasi, ikan lele sebanyak 5 lokasi, ikan nilai sebanyak 10 lokasi, dan ikan mas sebanyak 8 lokasi. Komoditi yang menghasilkan nilai LQ lebih besar 1 untuk ikan patin sebanyak 3 lokasi, ikan lele sebanyak 9 lokasi, ikan nila sebanyak 4 lokasi, dan ikan mas sebanyak 6 lokasi. Secara umum hasil LQ menunjukkan bahwa ikan lele lebih banyak lokasi yang menghasilkan nilai LQ $>1$. Komoditi ikan air tawar yang mempunyai nilai LQ paling tinggi dari komoditas lainnya adalah lele yang terletak pada Kabupaten Sambas sehingga wilayah tersebut dapat menjadi prioritas pengembangan. Pengembangan komoditas unggulan ikan air tawar pada wilayah Kabupaten Mempawah adalah ikan mas, ikan patin pada wilayah Kabupaten Kapuas Hulu, sedangkan ikan nila pada wilayah Kabupaten Sintang.

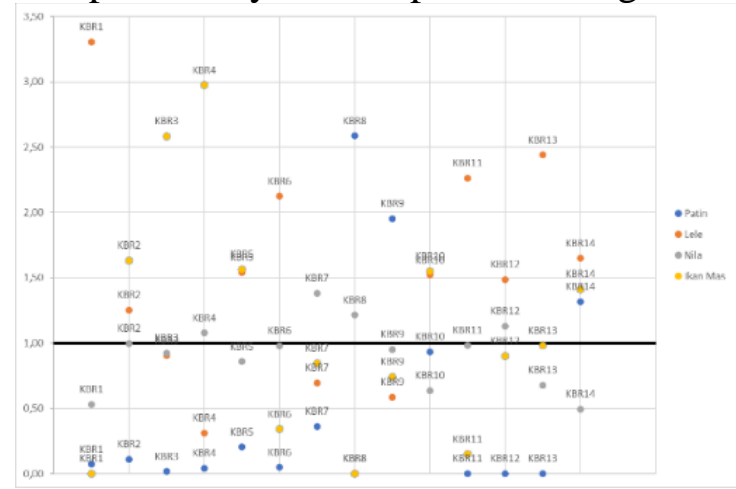

Gambar 2. Nilai LQ Ikan Air Tawar Kalimantan Barat

Komoditas Unggulan Ikan Air Tawar Kalimantan Utara

Produksi ikan air tawar yang paling rendah adalah Kalimantan Utara sebesar 291 ton dengan jenis ikan yang diproduksi adalah patin, lele, nila dan ikan mas terdapat pada 5 Kabupaten. Nilai LQ pada Gambar 3. yang lebih kecil dari 1 untuk 
ikan patin sebanyak 3 lokasi, ikan lele sebanyak 3 lokasi, ikan nila sebanyak 3 lokasi, dan ikan mas sebanyak 6 lokasi. Komoditas yang menghasilkan nilai LQ lebih besar 1 untuk ikan patin sebanyak 2 lokasi, ikan lele sebanyak 2 lokasi, ikan nila sebanyak 2 lokasi, dan ikan mas sebanyak 1 lokasi. Ikan mas pada provinsi Kalimantan Utara menghasilkan nilai LQ paling tinggi sebagai komoditas unggulan yang terletak pada wilayah Kabupaten Nunukan serta wilayah ini juga dapat mengembangkan ikan nila. Pengembangan ikan patin dapat dilakukan pada wilayah Kabupaten Malinau, ikan lele pada wilayah Kabupaten Tarakan.

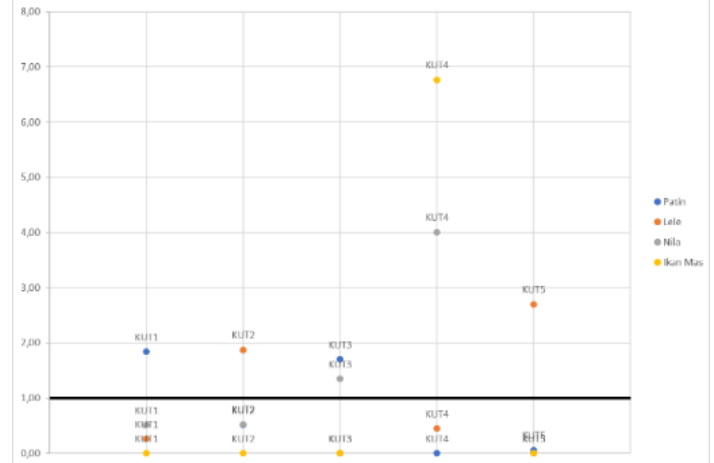

Gambar 3. Nilai LQ Ikan Air Tawar Kalimantan Utara

\section{Komoditas Unggulan Ikan Air Tawar Kalimantan Selatan}

Provinsi yang menghasilkan ikan gurami di pulau Kalimantan adalah Kalimantan Selatan dengan 13 Kabupaten/ Kota. [19] Pertumbuhan ikan gurami membutuhkan waktu yang lama atau lambat dan pada tebar yang tidak terlalu tinggi, akan tetapi mempunyai nilai jual yang tinggi dan relatif stabil.

Selain itu juga menghasilkan ikan patin, lele, nila dan ikan mas. Secara umum ikan yang dapat dikembangkan di provinsi ini karena menghasilkan komoditas unggulan adalah ikan nila pada wilayah Kabupaten Tanah Laut dan Kota Banjarmasin, ikan mas pada wilayah Kabupaten Tapin dan Kabupaten Balangan, ikan gurami pada Kabupaten Tanah Bumbu dan Kabupaten Balangan, Sedangkan ikan nila pada wilayah
Kabupaten Kotabaru dan ikan patin pada wilayah Hulu Sungai Utara. Pada Gambar 4. nilai LQ lebih kecil 1 menyebar pada 9 lokasi untuk ikan gurami, ikan patin sebanyak 9 lokasi, ikan lele sebanyak 5 lokasi, ikan nila sebanyak 5 lokasi, dan ikan mas sebanyak 6 lokasi. Penyebaran nilai LQ lebih besar 1 terletak pada 4 lokasi untuk ikan gurami, ikan patin sebanyak 4 lokasi, ikan lele sebanyak 8 lokasi, ikan nila sebanyak 8 lokasi, dan ikan mas sebanyak 7 lokasi.

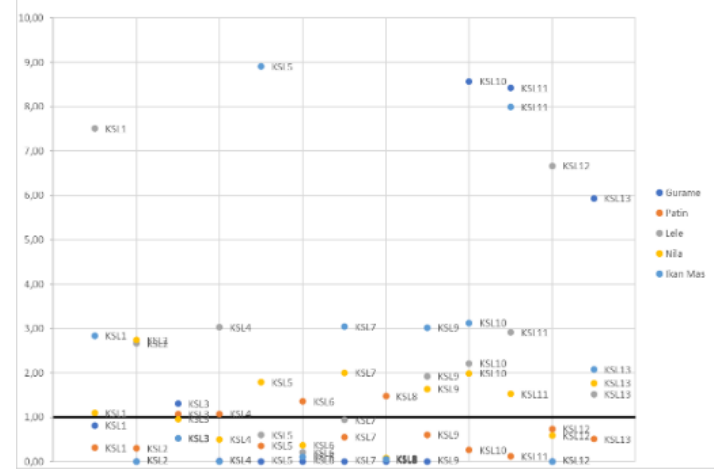

Gambar 4. Nilai LQ Ikan Air Tawar Kalimantan Selatan

\section{Komoditas Unggulan Ikan Air Tawar Kalimantan Tengah}

Kalimantan Tengah mempunyai 14 Kabupaten yang menghasilkan komoditas ikan air tawar, yaitu: patin, lele, nila dan ikan mas. Pengembangan komoditas unggulan karena menghasilkan nilai LQ > 1 pada wilayah Kabupaten Kapuas adalah ikan patin, ikan lele pada wilayah Kabupaten Gunung Mas, ikan nilai pada Kabupaten Pulang Pisau, dan ikan mas pada wilayah Kabupaten Barito Selatan dan Kabupaten Katingan. Wilayah pada Gambar 5. yang menghasilkan nilai LQ lebih rendah dari 1 sebanyak 13 lokasi untuk ikan patin, ikan lele sebanyak 5 lokasi, ikan nila sebanyak 2 lokasi, dan ikan mas sebanyak 4 lokasi. LQ lebih besar 1 terletak pada 1 lokasi untuk ikan patin, ikan lele sebanyak 9 lokasi, ikan nila sebanyak 12 lokasi, dan ikan mas sebanyak 10 lokasi. 


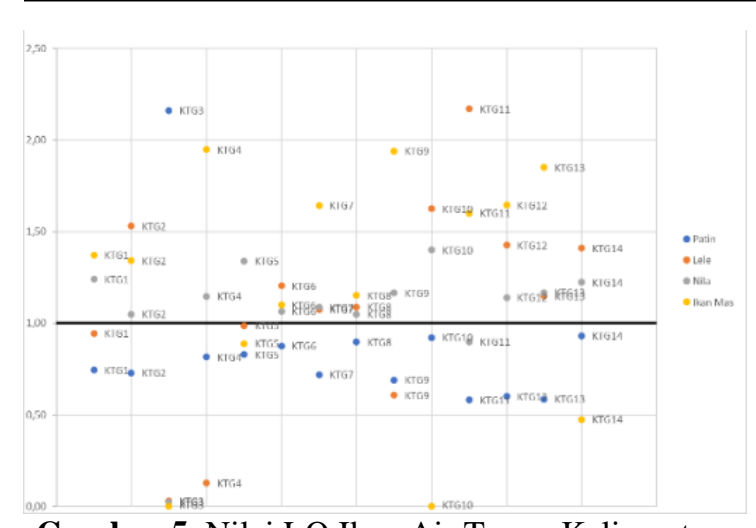

Gambar 5. Nilai LQ Ikan Air Tawar Kalimantan Tengah

Hasil perhitungan LQ pada Gambar 6. berdasarkan pulau Kalimantan sebagai wilayah acuan maka pengembangan komoditas ikan air tawar pada wilayah Kalimantan Selatan adalah ikan gurami dan ikan patin. [20] Hasil analisis kualitas air budidaya ikan patin dalam kolam dari 6 stasiun pengamatan 5 stasiun di Kalimantan Selatan menunjukkan nilai baik, dan 1 stasiun mempunyai nilai excellent.

Wilayah Kalimantan Utara adalah ikan lele, wilayah Kalimantan Barat adalah ikan lele dan ikan nila, wilayah Kalimantan Timur adalah ikan mas dan ikan nila, wilayah Kalimantan Tengah adalah ikan mas dan ikan lele. Prioritas pengembangan ikan lele terletak pada wilayah Kalimantan Utara, ikan gurami terletak pada wilayah Kalimantan Selatan, ikan mas pada wilayah Kalimantan Timur, ikan nila pada wilayah Kalimantan Barat, dan ikan patin pada wilayah Kalimantan Selatan.

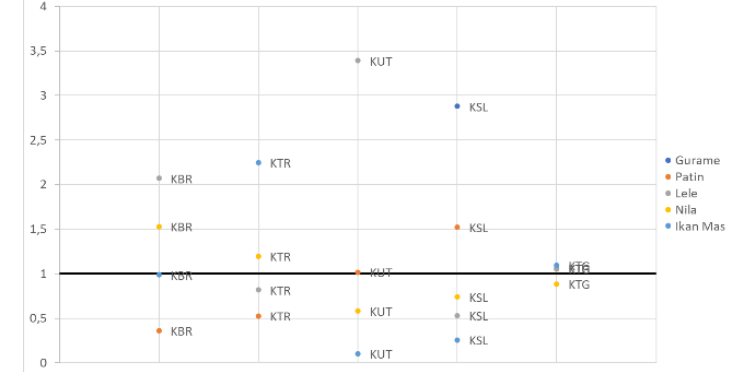

Gambar 6. Nilai LQ Ikan Air Tawar Pulau Kalimantan
Kontribusi Nilai Produksi Ikan Air Tawar Pulau Kalimantan

Pulau Kalimantan yang memberikan kontribusi nilai produksi tertinggi pada ikan gurami dan ikan patin tahun 2020 adalah Provinsi Kalimantan Selatan senilai Rp.52 milyar dan Rp.930 milyar. Nilai produksi ikan lele paling tinggi terletak pada wilayah Provinsi Kalimantan Barat senilai Rp.254 milyar. Ikan nila yang menghasilkan kontribusi tertinggi terhadap nilai produksi adalah Kalimantan Tengah senilai Rp.692 milyar. Sedangkan komoditi ikan mas yang memberikan nilai produksi tertinggi adalah Kalimantan Timur senilai Rp.502 milyar. [21] PDRB Kabupaten/ Kota dipengaruhi oleh produksi perikanan, tenaga kerja perikanan, investasi, [22] aset perikanan, dan [23] infrastruktur/ sarana dan prasarana perikanan.

Kontribusi ikan air tawar pada Tabel 1. terhadap total nilai produksi komoditi setiap provinsi (Kiv) di atas rata-rata sebesar $20 \%$ adalah wilayah Kalimantan Timur, Kalimantan Selatan, dan Kalimantan Tengah. Kontribusi ikan air tawar terhadap nilai produksi total nilai produksi sektor perikanan setiap provinsi (Kik) di atas rata-rata sebesar 16,29\% adalah Kalimantan Barat, Kalimantan Selatan dan Kalimantan Tengah. Kontribusi ikan air tawar terhadap total nilai produksi sektor perikanan pulau Kalimantan di atas rata-rata sebesar 3,6\% adalah wilayah Kalimantan Timur, Kalimantan Selatan, dan Kalimantan Tengah. 
Tabel 1. Persentase Kontribusi Ikan Air Tawar Pulau Kalimantan

\begin{tabular}{lrrr}
\hline \multicolumn{1}{c}{ Provinsi } & \multicolumn{1}{c}{ Kiv } & \multicolumn{1}{c}{ Kik } & \multicolumn{1}{c}{ Kil } \\
\hline & 22,97 & 14,47 & 4,13 \\
Kalimantan Timur & $\%$ & $\%$ & $\%$ \\
& 18,68 & 16,76 & 3,36 \\
Kalimantan Barat & $\%$ & $\%$ & $\%$ \\
& & & 0,03 \\
Kalimantan Utara & $0,14 \%$ & $0,28 \%$ & $\%$ \\
Kalimantan & 26,46 & 22,11 & 4,76 \\
Selatan & $\%$ & $\%$ & $\%$ \\
Kalimantan & 31,75 & 27,84 & 5,71 \\
Tengah & $\%$ & $\%$ & $\%$ \\
\hline
\end{tabular}

\section{KESIMPULAN}

Pulau Kalimantan secara umum menghasilkan komoditas utama ikan air tawar, yaitu: gurami, patin, lele, nila dan ikan mas yang tersebar pada 56 Kabupaten/ kota. Ikan lele mendominasi nilai LQ lebih besar 1 sebanyak 37 lokasi, sedangkan ikan nila sebanyak 30 lokasi, ikan mas sebanyak 25 lokasi, dan ikan patin sebanyak 12 lokasi. Dominasi komoditas unggulan ikan lele terletak pada wilayah Kalimantan Utara, ikan gurami terletak pada wilayah Kalimantan Selatan, ikan mas pada wilayah Kalimantan Timur, ikan nila pada wilayah Kalimantan Barat, dan ikan patin pada wilayah Kalimantan Selatan. Kalimantan Tengah memberikan kontribusi tertinggi karena menghasilkan jumlah dan nilai produksi rata-rata lebih unggul daripada provinsi lain. Saran yang dapat diberikan dari hasil penelitian ini adalah kebijakan pengembangan komoditas air tawar di Pulau Kalimantan dapat mempertimbangkan ikan lele dan ikan nila dan wilayah yang menjadi prioritas adalah Kalimantan Tengah dengan pengembangan ikan lele, ikan nila dan ikan mas.

\section{DAFTAR PUSTAKA}

[1] R. S. Pradana, "Kajian Komoditas Unggulan Perikanan Laut Tangkap Pada Setiap Kecamatan Di Kabupaten Aceh Jaya," J. Agrica, vol. 12, no. 2, pp. 62-76, 2019, doi: 10.31289/agrica.v12i2.2398.

[2] L. S. Syafei, "Keanekaragaman Hayati dan Konservasi Ikan Air Tawar," Perikanan, Sekol. Tinggi Perikanan, Jur. Penyul., vol. 11, no. 1, pp. 48-62, 2017.

[3] Y. H. Siska, M. S. Anwari, and A. Yani, "Keanekaragaman Jenis Ikan Air Tawar Di Sungai Kepari Dan Sungai Emperas Desa Kepari Kecamatan Sungai Laur Kabupaten Ketapang," vol. 8, no. 2, pp. 299-309, 2020.

[4] R. Irnawati, D. Simbolon, B. Wiryawan, B. Murdiyanto, and T. W. Nurani, "Analisis Komoditas Unggulan Perikanan Tangkap Di Taman Nasional Karimunjawa," J. Saintek Perikan., vol. 7, no. 1, pp. 1-9, 2011.

[5] D. R. Rokhmawati and Sardjito, "Penentuan Jenis Komoditas Unggulan Sub Sektor Perikanan Budidaya di Kabupaten Lamongan," J. Sains Dan Seni Its, vol. 8, no. 2, pp. 271-276, 2019.

[6] M. Ridwan, M. Kasmi, and A. R. S. Putri, "Penentuan Komoditas Unggulan Perikanan Laut Kabupaten Polewali Mandar Berdasarkan Data Statistik Tahun 2016," J. IPTEKS Pemanfaat. Sumberd. Perikan., vol. 5, no. 10, pp. 98-105, 2019, doi: 10.20956/jipsp.v5i10.6203.

[7] R. P. Sari, S. Gigentika, and T. D. Pramesthy, "Identifikasi Komoditas Unggulan Perikanan di Kabupaten Lombok Timur," Aurelia J., vol. 1, no. 2, pp. 71-82, 2020.

[8] M. Nazir, Metode Penelitian. Jakarta: PT Ghalia Indonesia, 2003.

[9] BPS Provinsi Kalimantan Timur, "Provinsi Kalimantan Timur Dalam Angka 2021," Kalimantan Timur, 2021.

[10] BPS Provinsi Kalimantan Barat, "Provinsi Kalimantan Barat Dalam Angka 2021," Kalimantan Barat, 2021.

[11] BPS Provinsi Kalimantan Utara, "Provinsi Kalimantan Utara Dalam Angka 2021," Kalimantan Utara, 2021.

[12] BPS Provinsi Kalimantan Selatan, "Provinsi Kalimantan Selatan Dalam 
Angka 2021,” Kalimantan Selatan, 2021.

[13] BPS Provinsi Kalimantan Tengah, "Provinsi Kalimantan Tengah Dalam Angka 2021," Kalimantan Tengah, 2021.

[14] Lutfi Muta'ali, Teknik Analisis Regional. Yogyakarta: Badan Penerbit Fakultas Geografi, 2015.

[15] M. Fattah, T. N. Utami, and C. A. Intyas, "Analysis of Potency and Probability of Subsector Development of Marine Fisheries Capture in Malang Regency," Econ. Soc. Fish. Mar., vol. 004, no. 02, pp. 135-143, 2017, doi: 10.21776/ub.ecsofim.2017.004.02.03.

[16] W. Al Farizi, M. Sari, and M. Fattah, "Analisis Kontribusi Dan Daya Saing Ekspor Sektor Perikanan Provinsi Nusa Tenggara Barat," J. Fish. Mar. Res., vol. 4, no. 1, pp. 46-52, 2020, doi: 10.1201/9780203911518-11.

[17] F. Alam Masruri, Cahyono, and Nugrahana Fitria Ruhyana, "Analisis Penentuan Sektor Unggulan di Kabupaten Sumedang Provinsi Jawa Barat," Coopetition J. Ilm. Manaj., vol. 12, no. 1, pp. 31-44, 2021, doi: 10.32670/coopetition.v12i1.283.

[18] U. Windi, N. Istiqamah, and Muslimah, "Identifikasi Potensi Perikanan Air Tawar Di Desa Perigi Landu Kecamatan Sejangkung Kabupaten Sambas," J. Nekt., vol. 1, no. 1, pp. 3643, 2021.

[19] M. Fattah, T. N. Utami, and D. Sofiati,
"Financial Feasibility And Sensitivity Of Gouramy Culture (Osphronemus gouramy) Business At Susuhbango Village, Kediri Regency," J. Econ. Soc. Fish. Mar., vol. 06, no. 02, pp. 202208, 2019, [Online]. Available: http://dx.doi.org/10.21776/ub.ecsofim. 2019.006.02.08\%0Ae-ISSN:

[20] I. Febrianty, "Daya Dukung Kualitas Air Terhadap Usaha Budidaya Ikan Patin Dalam Kolam Di Kabupaten Banjar Kalimantan Selatan," EnviroScienteae, vol. 16, no. 1, pp. 7276 , 2020, doi: 10.1088/17518113/44/8/085201.

[21] Y. Mardyani and A. Yulianti, "Analisis Pengaruh Sub Sektor Perikanan Terhadap Pertumbuhan Ekonomi Di Provinsi Kepulauan Bangka Belitung," Equity J. Ekon., vol. 8, no. 2, pp. 41-50, 2020, doi: 10.33019/equity.v8i2.47.

[22] P. Dianissa, "Analisis Pengaruh FaktorFaktor Subsektor Perikanan Terhadap Produk Domestik Regional Bruto Provinsi Sumatera Utara," J. Manaj. Tools, vol. 9, no. 1, pp. 29-50, 2018.

[23] E. S. Luhur, S. H. Suryawati, and T. Kurniawan, "Kontribusi Sektor Perikanan Dalam Pembangunan Wilayah Kabupaten Rote Ndao: Pendekatan Location Quotient (LQ) Dan Shift Share (SS)," Bul. Ilm. Mar. Sos. Ekon. Kelaut. dan Perikan., vol. 5, no. 1, pp. 11-19, 2019, doi: 10.15578/marina.v5i1.7712. 